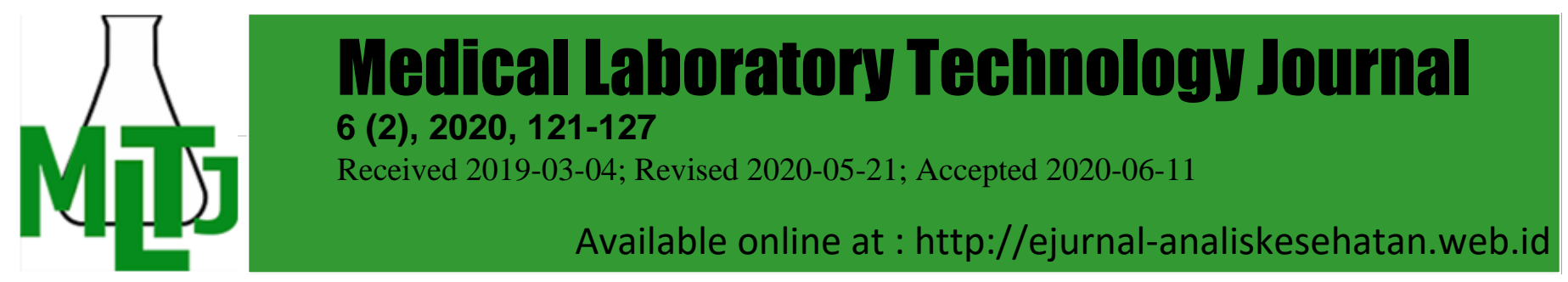

\title{
Comparative Test of Ret-He Examination in Diagnosis of Iron Deficiency in Pregnant Women
}

\section{Gilang Nugraha $^{1^{\star}}$, Nur Masruroh ${ }^{2}$, Diyan Wahyu Kurniasari ${ }^{3}$}

${ }^{1}$ Department of Medical Laboratory Technology, Faculty of Health, Universitas Nahdlatul Ulama Surabaya, Indonesia. ${ }^{2}$ Department of Midwifery, Faculty of Nursing and Midwifery, Universitas Nahdlatul Ulama Surabaya, Indonesia. ${ }^{3}$ Department of Medical, Faculty of Medical, Universitas Nahdlatul Ulama Surabaya, Indonesia.

*Email : gilang@unusa.ac.id

DOI: $10.31964 / \mathrm{mltj} . v 0 i 0.303$

\begin{abstract}
The most common cause of anemia is iron deficiency, which found in $50 \%$ of anemia cases. There are $66.7 \%$ of pregnant women in Indonesia that still lack iron intake. Reticulocyte hemoglobin equivalent (Ret-He) examination as a single parameter is the initial indicator of iron deficiency, considered more sensitive in detecting iron reserves in the body. This study aims to determine the effectivity of the Ret-He examination as a single parameter in establishing the diagnosis of iron deficiency in pregnant women. This research was conducted on 30 pregnant women. The sensitivity, specificity, and predictive value of Ret-He were determined by comparing the results of the biochemical examination of iron profiles. Iron deficiency defined as an abnormal examination result on two or more biochemical parameters, which were SI $<50 \mu \mathrm{g} / \mathrm{dL}$, TIBC $>425 \mu \mathrm{g} / \mathrm{dL}$, serum ferritin $<10 \mathrm{ng} / \mathrm{mL}$ and Transferrin Saturation $<15.0 \%$. Between 30 pregnant women, there were $18(60 \%)$ with iron deficiency and 12 (40\%) without iron deficiency. Ret-He levels were significantly lower in pregnant women with iron deficiency $(P=0.008)$. A decrease in the Ret-He level in iron deficiency positively correlated with serum Ferritin $(r=0.433)$. The effectivity of the Ret-He examination had an AUC value of 0.785 ( $\mathrm{P}=0.009)$. Ret-He diagnostic reliability had at a cut-off value of $27.2 \mathrm{pg}$ with sensitivity $(87.5 \%)$, specificity $(50.0 \%)$, positive predictive value (38.9\%), and negative predictive value (91.7\%). Ret-He examination is a useful marker of iron deficiency in pregnant women so that it can be applied for screening or as a routine examination.
\end{abstract}

Keyword: Ret-He; iron deficiency; pregnant women

\section{INTRODUCTION}

According to the World Health Organization (WHO), about 1.5 billion people or around $42 \%$ worldwide suffer from anemia (Api, Breyman, Çetiner, Demir, \& Ecder, 2015). Anemia in pregnant women in Indonesia based on Riskesdas 2013 reached $37.1 \%$ (Ministry of Health Republic of Indonesia, 2013). The most common cause of anemia is iron deficiency, which found in $50 \%$ of cases of anemia. There are $66.7 \%$ of pregnant women in Indonesia that still have insufficient iron intake(Api et al., 2015; Ministry of Health Republic of Indonesia, 2013; Roosleyn, 2016). Iron deficiency anemia in pregnant women can impact on maternal death, infant mortality, congenital defects, premature birth, low birth weight babies (LBW), and anemia in babies (Roosleyn, 2016). If this does not receive individual attention, maternal and infant mortality, and morbidity in Indonesia will be challenging to reduce.

Recently, hematological examination offers a new parameter for assessing the body's iron reserves that considered to be able to replace the conventional iron 
reserves examination. Sysmex Corporation introduced the reticulocyte hemoglobin equivalent (Ret-He) (Keohane, Smith, \& Walenga, 2016; Peerschke, Pessin, \& Maslak, 2014). Conventional iron reserves examination (iron profile examination) has been carried out by biochemical examination that measures more than one parameter, namely serum iron (SI), total iron-binding capacity (TIBC), transferrin saturation (TSAT) and serum ferritin (Johnson Wimbley \& Graham, 2011; Wu, Lesperance, \& Bernstein, 2011). Ret-He examination is a single parameter that directly measures iron levels in reticulocytes, which is an early indicator of iron deficiency. This examination is considered more sensitive in detecting iron reserves in the body (Rungngu, Wahani, \& Mantik, 2016; Sysmex, 2016).

Reticulocytes are precursors (young cells) of erythrocytes formed in the bone marrow and mature for two to four days in circulation. Reticulocyte examination has often used to assess the quantity of erythropoiesis. Measurement of hemoglobin level on reticulocytes can assess iron supply as an indicator of the quality of erythropoiesis. An examination of hemoglobin content on reticulocytes can detect changes in iron status much earlier than the examination of erythrocytes (Sysmex, 2016).

We aim to find the effectivity of the Ret-He examination as a single parameter in establishing the diagnosis of iron deficiency in pregnant women. Because during pregnancy, physiological changes occur in the body that can affect the results of the examination. This study focuses on diagnostic reliability by measuring the sensitivity, specificity, and predictive value of the examination.

\section{MATERIALS AND METHOD \\ Patients and study design}

Thirty pregnant women visited the Jagir Community Health Center (Puskesmas), Surabaya in May 2019 was taken as respondents. This study was approved by the ethics committee of the Nahdlatul Ulama University Surabaya with the Ethical Clearance Number 101/EC/KEPK/UNUSA/2019. We conducted a survey to get pregnant women with and without iron deficiency. The survey was conducted by interviewing and looking at the patient's medical records. We excluded pregnant women who were sick or had a history of chronic illness.

Venous blood sampling performed according to the phlebotomy protocol. Each respondent of pregnant women had blood drawn in the antecubital vein. The blood accommodated using a red-capped BD Vacutainer ${ }^{\circledR}$ tube $(13 \times 75 \mathrm{~mm})$, which does not contain additives and a purple capped containing EDTA anticoagulant. Each tube filled with $3 \mathrm{~mL}$ of blood.

Blood on the purple tube examined for Ret-He using Sysmex XN-1000 (Sysmex Corporation Kobe, Japan). Blood in the red tube examined using the Ci8200 Architect tool (Abbott Laboratories, USA) for the serum iron (SI), total iron-binding capacity (TIBC), and serum ferritin. TSAT determined by serum iron divided by TIBC times $100 \%$.

Iron deficiency defined as an abnormal examination result on two or more biochemical parameters that have measured. Abnormal values that were used to determine iron deficiency were $\mathrm{SI}<50 \mu \mathrm{g} / \mathrm{dL}, \mathrm{TIBC}>425 \mu \mathrm{g} / \mathrm{dL}$, serum ferritin $<10$ $\mathrm{ng} / \mathrm{mL}$ and TSAT $<15.0 \%$. The cut-off value of examination based on the laboratory where the examination was referred to, which was the Indonesian Pramita Laboratory.

\section{Statistical Analysis}

Data were analyzed using Microsoft Excel 2013 (Microsoft, US) and SPSS version 16 (IBM, Armonk, NY, USA). A Chi-Square test used to distinguish between 
two groups. Pearson correlation test used to determine the relationship of Ret-He with biochemical parameters. Sensitivity, specificity, and predictive value of Ret-He tests determined by comparing it against the results of SI, TIBC, serum ferritin, and TSAT tests. Tests carried out using crosstab analysis on Microsoft Excel, Sensitivity, specificity, and the predictive value calculated using formulas:

Sensitivity $(\%)=\frac{\text { True Positive }}{\text { True Positive }+ \text { False Negative }}$

Specificity $(\%)=\frac{\text { True Negative }}{\text { True Negative }+ \text { False Positive }}$

Positive Predictive Value $(\%)=\frac{\text { True Positive }}{\text { True Positive }+ \text { False Positive }}$

Negative Predictive Value $(\%)=\frac{\text { True Negative }}{\text { True Negative }+ \text { False Negative }}$

ROC curves used to determine diagnostic performance by selecting the value of the area under the curve (AUC).

\section{RESULTS AND DISCUSSION}

This study took 30 pregnant women respondents at Jagir Puskesmas, Surabaya, Indonesia. During the study, we obtained 33 respondents. Of these, three respondents did not qualify because they were sick and had a history of chronic illness. The characteristics of respondents can be seen in Table 1. The study was dominated by pregnant women aged $<35$ years (86.7\%) with a range of $17-41$ years, the gestational age of the third trimester of pregnancy (93.3\%) with a range of $13-40$ weeks, educated in high school and worked as a housewife.

Table 1. Characteristics of Research Respondents

\begin{tabular}{|c|c|c|c|}
\hline \multicolumn{2}{|c|}{ Characteristic } & Total & Percentage (\%) \\
\hline \multirow{3}{*}{ Age } & $<35$ years & 26 & 86.7 \\
\hline & $\geq 35$ years & 4 & 13.3 \\
\hline & $1 s t$ & 1 & 3.3 \\
\hline \multirow[t]{4}{*}{ Trimester } & 2nd & 1 & 3.3 \\
\hline & 3rd & 28 & 93.3 \\
\hline & $1 \mathrm{st}$ & 10 & 33.3 \\
\hline & 2nd & 13 & 43.3 \\
\hline \multirow[t]{4}{*}{ Pregnancy } & 3rd & 4 & 13.3 \\
\hline & 4th & 2 & 6.7 \\
\hline & 5th & 1 & 3.3 \\
\hline & $\begin{array}{l}\text { Elementary } \\
\text { School }\end{array}$ & 3 & 10.0 \\
\hline \multirow[t]{4}{*}{ Education } & Middle School & 8 & 26.7 \\
\hline & High School & 14 & 46.7 \\
\hline & Bachelor & 5 & 16.7 \\
\hline & Housewife & 18 & 60.0 \\
\hline \multirow[t]{2}{*}{ Occupation } & Private Employee & 11 & 36.7 \\
\hline & College Student & 1 & 3.3 \\
\hline
\end{tabular}

The characteristics of the laboratory test results can be seen in Table 2. We found a significant difference in the examination results between the iron deficiency group and the non-iron deficiency group. 
Table 2. Characteristics of The Ret-He Examination and Biochemical Test Results in Pregnant Women

\begin{tabular}{|c|c|c|c|c|c|}
\hline \multirow{2}{*}{ Parameter } & \multicolumn{2}{|c|}{ Non-iron Deficiency } & \multicolumn{2}{|c|}{ Iron Deficiency } & \multirow{2}{*}{$P$} \\
\hline & Mean & SD & Mean & SD & \\
\hline Ret-He (pg) & 40.0 & 2.3 & 28.0 & 3.1 & 0.008 \\
\hline Serum Iron $(\mu \mathrm{g} / \mathrm{dL})$ & 90.8 & 45.3 & 75.8 & 92.5 & 0.005 \\
\hline TIBC $(\mu \mathrm{g} / \mathrm{dL})$ & 360.0 & 55.6 & 466.2 & 42.1 & 0.000 \\
\hline Serum Ferritin (ng/mL) & 33.2 & 38.0 & 10.7 & 7.8 & 0.001 \\
\hline TSAT (\%) & 24.8 & 9.8 & 15.7 & 17.4 & 0.000 \\
\hline
\end{tabular}

Based on the results of the biochemical test, $8(26.7 \%)$ of the pregnant women had an abnormal SI, 17 (56.7\%) had an abnormal TIBC, $11(36.7 \%)$ had an abnormal serum ferritin and $15(50,0 \%)$ had an abnormal TSAT. Based on the diagnosis from clinical pathologist, 18 (60\%) pregnant women had iron deficiency.

\section{Correlation between Ret-He and Iron Profile Parameters}

Ret-He levels were positively correlated with serum ferritin $(r=0.4433 ; p=$ $0.017)$ and negatively correlated with TIBC $(r=-0.504 ; p=0.005)$. Ret-He does not correlate with Serum Iron $(r=-0.047 ; p=0.805)$ and TSAT $(r=0.112 ; r=0.556)$. Table 3 shows the correlation of Ret-He with SI, TIBC, serum ferritin and TSAT.

Table 3. Correlations between Biochemical Tests and Ret-He

\begin{tabular}{lcc}
\hline & Correlation & $p$-value \\
\hline Serum Iron & -0.047 & 0.805 \\
TIBC & -0.504 & 0.005 \\
Serum Ferritin & 0.433 & 0.017 \\
TSAT & 0.112 & 0.556 \\
\hline
\end{tabular}

\section{Effectivity of Ret-He in Diagnosing Iron Deficiency}

The ROC curve shown in Figure 1 used to determine the diagnostic performance of Ret-He in iron deficiency of pregnant women. This test carried out by comparing the result of the Ret-He test to the result of the iron profile biochemical test. ROC curve analysis shows that with $\mathrm{SI}<50 \mu \mathrm{g} / \mathrm{dL}$, TIBC $>425 \mu \mathrm{g} / \mathrm{dL}$, serum ferritin $<10 \mathrm{ng} / \mathrm{mL}$ and TSAT $<15.0 \%$, the area under the curve (AUC) obtained was 0.785 (P $=0.009$ ).

The sensitivity, specificity, and predictive value of the Ret-He examination on biochemical tests with a cut-off value of $27.2 \mathrm{pg}$ are presented in Table 3 and Tabel 4 (Brugnara, Schiller, \& Moran, 2006). Ret-He has a pretty good sensitivity (87.5\%) and a negative forecast value $(91.7 \%)$, but not with its specificity value $(50.0 \%)$ and positive predictive value (38.9\%). 


\section{ROC Curve}

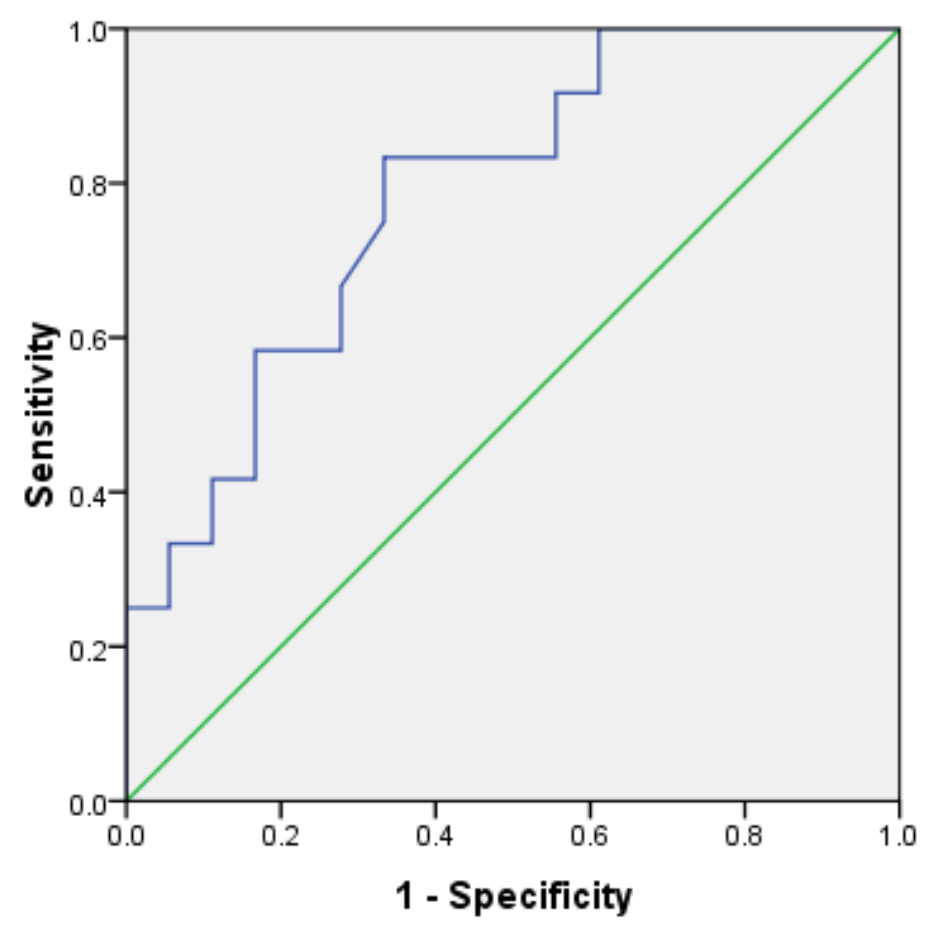

Figure 1. Analysis of The Ret-He ROC Curve in Diagnosing Iron Deficiency in Pregnant Women

Tabel 3. Crosstab Ret-He with biochemical tests

\begin{tabular}{lcc}
\hline \multirow{2}{*}{ Ret-He } & \multicolumn{2}{c}{ Biochemical Test } \\
& Iron Deficiency & Non-iron Deficiency \\
\hline Iron Deficiency & 7 & 11 \\
Non-iron Deficiency & 1 & 11 \\
\hline
\end{tabular}

Table 4. Sensitivity, specificity and predictive value in diagnosing iron deficiency

\begin{tabular}{ll}
\hline & Result \\
\hline Sensitivity (\%) & 87.5 \\
Specificity (\%) & 50.0 \\
Positive Predictive Value (\%) & 38.9 \\
Negative Predictive Value (\%) & 91.7 \\
\hline
\end{tabular}

Pregnant women are very susceptible to anemia, especially iron deficiency. This condition occurs because, during pregnancy, fetal hepcidin controls the transfer of iron from the maternal placenta to the fetal circulation. When the concentration of hepcidin is low, iron-regulated into the blood plasma and the level becomes high. When hepcidin level is high, iron transferred into enterocytes, macrophages, and hepatocytes. The need for external iron remains low, between 1 to $8 \mathrm{mg}$ daily, but the need for iron increases for fetal and placental development during pregnancy (Khalafallah \& Dennis, 2012; Warner \& Kamran, 2017). 
Early diagnosis of iron deficiency can be made by conducting a biochemical test of the iron profile, which are serum iron (SI), total iron-binding capacity (TIBC), serum ferritin, and TSAT (Uçar et al., 2019). Various parameters of examination can have an impact on the burden of costs incurred on the patient. Therefore this study proposes a Ret-He examination in pregnant women to assess the body's iron reserves because it is faster and does not incur additional costs and can be measured simultaneously with other hematological examinations (Keohane et al., 2016; Peerschke et al., 2014).

We evaluated 30 pregnant women consisting of $18(60 \%)$ with iron deficiency and $12(40 \%)$ without iron deficiency. Ret-He level was significantly lower in the iron deficiency group than in the non-iron deficiency group. The decrease in the Ret-He level in iron deficiency positively correlated with serum Ferritin $(r=0.433)$. This means that Ret-He can be a good predictor in assessing bone marrow iron storage (Mehta et al., 2016).

The effectivity of the Ret-He examination obtained an AUC value of $0.785(P=$ 0.009 ). Ret-He diagnostic reliability obtained at a cut-off value of $27.2 \mathrm{pg}$ with sensitivity (87.5\%), specificity (50.0\%), positive predictive value (38.9\%) and negative predictive value (91.7\%). Toki et al. (2017) showed that Ret-He could be a useful clinical marker in diagnosing iron deficiency (Toki et al., 2017). Mehta et al. (2016) proved Ret-He to be an excellent marker in assessing bone marrow iron storage (Mehta et al., 2016). Ret-He can give good results in cancer patients and chronic kidney failure (Eguchi, Tsuchiya, Tsukada, \& Nitta, 2010; Peerschke et al., 2014).

One of the limitations of this study is that it does not carry out the CRP examination. CRP increase as a marker of inflammation. This condition is a marker of the accuracy of serum ferritin tests because the limitation of serum ferritin is that the presence of inflammation influences it. After all, it is an acute-phase protein (Dignass, Farrag, \& Stein, 2018). Also, the small number of samples and research conducted in one region contributed to the study's limitations.

\section{CONCLUSION}

Our results show that the Ret-He examination is a pretty good marker of iron deficiency in pregnant women. It can be applied for screening or can be applied as a routine examination.

\section{ACKNOWLEDGEMENT}

The authors are thankful for the grants from the Ministry of Research and the Higher Education Republic of Indonesia. We are also thankful for the technical assistance provided by the Jagir Health Center and Pramita Clinical Laboratory.

\section{CONFLICT OF INTEREST}

The authors have no potential conflicts of interest concerning this study.

\section{REFERENCE}

Api, O., Breyman, C., Çetiner, M., Demir, C., \& Ecder, T. (2015). Iron deficiency anemia, working group consensus report, and the diagnosis and treatment of iron deficiency anemia during pregnancy and the postpartum period. Journal of Turkish Society of Obstetrics and Gynecology, 12(3), 173-181. https://doi.org/10.4274/tjod.01700 
Brugnara, C., Schiller, B., \& Moran, J. (2006). Reticulocyte hemoglobin equivalent (Ret $\mathrm{He})$ and assessment of iron-deficient states. Clinical and Laboratory Haematology, 28(5), 303-308. https://doi.org/10.1111/j.1365-2257.2006.00812.x

Dignass, A., Farrag, K., \& Stein, J. (2018). Limitations of Serum Ferritin in Diagnosing Iron Deficiency in Inflammatory Conditions. International Journal of Cronic Disease, 2018, 1-11. https://doi.org/10.1155/2018/9394060

Eguchi, A., Tsuchiya, K., Tsukada, M., \& Nitta, K. (2010). Clinical usefulness of reticulocyte hemoglobin equivalent $(\mathrm{RET}-\mathrm{He})$ in patients at the pre-dialysis and in patients on peritoneal dialysis. Japanese Journal of Nephrology, 52(2), 132-140.

Johnson Wimbley, T. D., \& Graham, D. Y. (2011). Diagnosis and management of iron deficiency anemia in the 21st century. Therapeutic Advances in Gastroenterology, 4(3), 177-184. https://doi.org/10.1177/1756283X11398736

Keohane, E. M., Smith, L. J., \& Walenga, J. M. (2016). Rodaks's Hematology: Clinical Principles and Application (5th ed.). Missouri: Elsevier.

Khalafallah, A. A., \& Dennis, A. E. (2012). Iron deficiency anemia in pregnancy and postpartum: Pathophysiology and effect of oral versus intravenous iron therapy. Journal of Pregnancy, 2012. https://doi.org/10.1155/2012/630519

Mehta, S., Goyal, L. K., Kaushik, D., Gulati, S., Sharma, N., Harshvardhan, L., \& Gupta, N. (2016). Reticulocyte hemoglobin vis-a-vis serum ferritin as a marker of bone marrow iron store in iron deficiency anemia. Journal of Association of Physicians of India, 64(11), 38-42.

Ministry of the Health Republic of Indonesia. (2013). Basic Health Research, 2013.

Peerschke, E. I. B., Pessin, M. S., \& Maslak, P. (2014). Using the hemoglobin content of reticulocytes (RET-He) to evaluate anemia in patients with cancer. American Journal of Clinical Pathology, 142(4), 506-512. https://doi.org/10.1309/AJCPCVZ5B0BOYJGN

Roosleyn, I. P. T. (2016). Strategies in Preventing Anemia in Pregnancy. Jurnal IImiah Widya, 3(3), 1-9. https://doi.org/ISSN 2337-6686

Rungngu, S. L. P., Wahani, A., \& Mantik, M. F. J. (2016). Reticulocyte Hemoglobin Equivalent for Diagnosing Iron Deficiency Anemia in Children. Paediatrica Indonesiana, 56(2), 90-94. https://doi.org/92 41546123

Sysmex. (2016). Reticulocyte Haemoglobin Equivalent - Ret-He. Retrieved from http://www.sysmex-europe.com/academy/knowledge-centre/sysmexparameters/reticulocyte-haemoglobin-equivalent-ret-he.html

Toki, Y., Ikuta, K., Kawahara, Y., Niizeki, N., Kon, M., Enomoto, M., ... Okumura, T. (2017). Reticulocyte hemoglobin is equivalent to a potential marker for the diagnosis of iron deficiency. International Journal of Hematology, 106(1), 116125. https://doi.org/10.1007/s12185-017-2212-6

Uçar, M. A., Falay, M., Dağdas, S., Ceran, F., Urlu, S. M., \& Özet, G. (2019). The importance of RET-He in the diagnosis of iron deficiency and iron-deficiency anemia and the evaluation of response to oral iron therapy. Journal of Medical Biochemistry, 38(4), 496-502. https://doi.org/10.2478/jomb-2018-0052

Warner, M. J., \& Kamran, M. T. (2017). Anemia, Iron Deficiency. Retrieved from https://www.ncbi.nlm.nih.gov/books/NBK448065/

Wu, A. C., Lesperance, L., \& Bernstein, H. (2011). Screening for Iron Deficiency. Pediatrics in Review, 23(5), 171-178. 